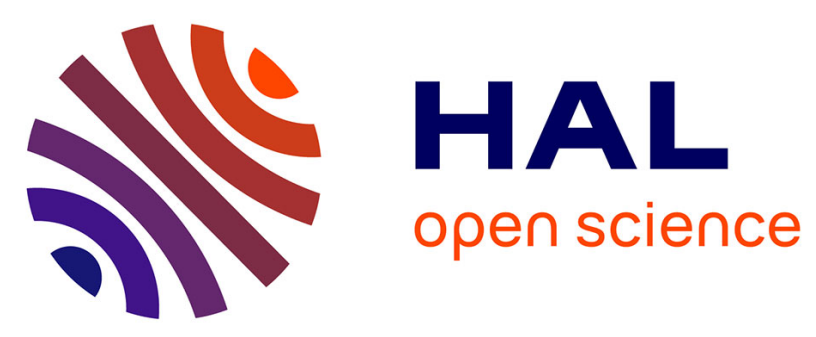

\title{
Pseudomyxoma peritonei: a French multicentric study of 301 patients treated with cytoreductive surgery and intraperitoneal chemotherapy
}

D. Elias, F. Gilly, F. Quenet, Jm. Bereder, L. Sideris, B. Mansvelt, G. Lorimier, O. Glehen

\section{To cite this version:}

D. Elias, F. Gilly, F. Quenet, Jm. Bereder, L. Sideris, et al.. Pseudomyxoma peritonei: a French multicentric study of 301 patients treated with cytoreductive surgery and intraperitoneal chemotherapy. EJSO - European Journal of Surgical Oncology, 2010, 36 (5), pp.456. 10.1016/j.ejso.2010.01.006 . hal-00594804

\section{HAL Id: hal-00594804 \\ https://hal.science/hal-00594804}

Submitted on 21 May 2011

HAL is a multi-disciplinary open access archive for the deposit and dissemination of scientific research documents, whether they are published or not. The documents may come from teaching and research institutions in France or abroad, or from public or private research centers.
L'archive ouverte pluridisciplinaire HAL, est destinée au dépôt et à la diffusion de documents scientifiques de niveau recherche, publiés ou non, émanant des établissements d'enseignement et de recherche français ou étrangers, des laboratoires publics ou privés. 


\section{Accepted Manuscript}

Title: Pseudomyxoma peritonei: a French multicentric study of 301 patients treated with cytoreductive surgery and intraperitoneal chemotherapy

Authors: D. Elias, F. Gilly, F. Quenet, JM. Bereder, L. Sideris, B. Mansvelt, G. Lorimier, O. Glehen

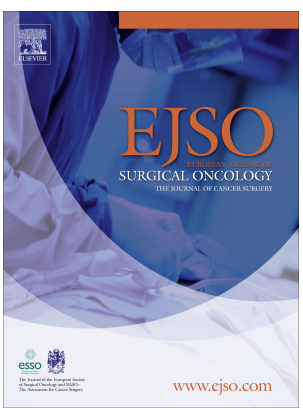

PII: $\quad$ S0748-7983(10)00031-4

DOI: $\quad$ 10.1016/j.ejso.2010.01.006

Reference: $\quad$ YEJSO 2935

To appear in: European Journal of Surgical Oncology

Received Date: 11 November 2009

Accepted Date: 18 January 2010

Please cite this article as: Elias D, Gilly F, Quenet F, Bereder JM, Sideris L, Mansvelt B, Lorimier G, Glehen O. Pseudomyxoma peritonei: a French multicentric study of 301 patients treated with cytoreductive surgery and intraperitoneal chemotherapy, European Journal of Surgical Oncology (2010), doi: $10.1016 / j$.ejso.2010.01.006

This is a PDF file of an unedited manuscript that has been accepted for publication. As a service to our customers we are providing this early version of the manuscript. The manuscript will undergo copyediting, typesetting, and review of the resulting proof before it is published in its final form. Please note that during the production process errors may be discovered which could affect the content, and all legal disclaimers that apply to the journal pertain. 
Pseudomyxoma peritonei: a French multicentric study of 301 patients treated with cytoreductive surgery and intraperitoneal chemotherapy.

D. Elias ${ }^{1}, M D, P h D$,

F. Gilly ${ }^{2}, M D, P H D$,

F. Quenet ${ }^{3}, M D$,

JM. Bereder ${ }^{4}, M D$

L. Sidéris ${ }^{5}, M D$,

B. Mansvelt ${ }^{6}, M D$

G. Lorimier ${ }^{7}, M D$

O. Glehen ${ }^{2}, M D$, PhD,

And the Association Française de Chirurgie

${ }^{1}$ Institut Gustave Roussy, Villejuif.

${ }^{2}$ Center Hospitalo-Universitaire Lyon-sud

${ }^{3}$ Center Val d'Aurel, Montpellier

${ }^{4}$ Center Hospitalo-Universitaire, Nice

${ }^{5}$ Hopitâl Maisonneuve, Montréal

${ }^{6}$ Hopital Jolimont, Haine St Paul

${ }^{7}$ Center Paul Papin, Angers

Corresponding author: Dominique ELIAS

Chief - Department of Oncologic Surgery

39 Rue Camille Desmoulins

94805, Villejuif, Cédex,

France

e-mail: elias@igr.fr 


\section{Miniabstract :}

The results obtained in 301 patients with pseudomyxoma peritonei treated by cytoreductive surgery combined with perioperative intraperitoneal chemotherapy in 18 French-speaking centers confirms good results and that these procedures should be recommended in specialized centers.

\section{STRUCTURED ABSTRACT}

\section{Objective :}

To analyze a large series of patients with pseudomyxoma peritonei (PMP) treated with cytoreductive surgery associated with perioperative intraperitoneal chemotherapy (PIC) in 18 French-speaking centers.

\section{Patients and methods:}

From March 1993 to December 2007, 301 patients with diffuse PMP were treated by cytoreductive surgery with PIC. Complete cytoreductive surgery was achieved in 219 patients (73\%), and hyperthermic intraperitoneal chemotherapy (HIPEC) was performed in 255 (85\%), mainly during the latter period of the study.

\section{Results:}

Postoperative mortality and morbidity were $4.4 \%$ and $40 \%$, respectively. The mean follow-up was 88 months. The 5 -year overall and disease-free survival rates were $73 \% \%$ and $56 \%$, respectively. The multivariate analysis identified 5 prognostic factors : the extent of peritoneal seeding $(p=0.004)$, the center $(p=0.0004)$, the pathologic grade $(p=0.03)$, gender $(p=0.02)$, and the use of HIPEC $(p=0.04)$. When only the 206 patients with complete cytoreductive surgery were considered, the extent of peritoneal seeding was the only significant prognostic factor $(p=0.004)$.

\section{Conclusion:}


This large multicentric retrospective study confirms that cytoreductive surgery combined with PIC (with the use of hyperthermia) should be considered as the gold standard treatment of PMP and should be performed in specialized centers. It underlines the prognostic impact of the extent of peritoneal seeding, especially in patients treated by complete cytoreductive surgery. This prognostic impact appears to be greater than that of the pathologic grade.

Key-words: peritoneal pseudomyxoma, cytoreductive surgery, intraperitoneal chemotherapy, hyperthermia, prognosis; 
Pseudomyxoma peritonei (PMP) is a clinico-pathologic entity characterized by the production of mucinous ascites $(1,2)$ and mostly originates from appendiceal epithelial neoplasms. The tumor grows, obstructing the narrow lumen of the appendix and subsequently leading to appendiceal perforation $(1,2)$. Then neoplastic cells progressively and slowly colonize the peritoneal cavity and copious mucin production builds up in the peritoneal cavity. Recently, pathologic enteric bacteria were shown to be present in all specimens and their density was correlated with the prognosis (3). Appendix tumors causing PMP range from a benign pathologic appearance (disseminated peritoneal adenomucinosis or DPAM), to malignant pathologic findings (peritoneal mucinous carcinomatosis or PMCA), with some intermediate pathologic grades (4). Clinically, this syndrome ranges from early PMP fortuitously discovered on imaging or during a laparotomy performed for another reason, to advanced cases with a distended abdomen, occlusive syndrome and starvation.

The conventional treatment of PMP is surgical debulking repeated, as necessary to alleviate pressure effects $(5,6)$. However, this treatment is palliative, leaving visible or occult disease in the peritoneal cavity. Repeated debulking surgeries become ever more difficult due to progressively thickened intra-abdominal adhesions (7).

A combination of cytoreductive surgery (CRS) with perioperative intraperitoneal chemotherapy (PIC) was proposed by Sugarbaker (8). The rationale behind this strategy was to resect visible disease and any occult residual disease would be treated with a high concentration of chemotherapy and hyperthermia which mutually potentiate one another's effects $(9,10)$. Fifteen years and 600 publications later $(7)$, a systematic review of this novel treatment concluded that this combined approach was very probably superior to conventional therapy, even in the absence of controlled 
randomized trials, and even with evidence from only five series of more than 100 cases (11-16). Each series reported the experience of only one team with various experiences, and there was no multicentric series reflecting "reality".

This study aimed to collect patients with PMP treated with this combined approach in 18 different French-speaking centers, to analyze morbidity, mortality and survival results, and to identify the main prognostic factors for better patient selection.

\section{Patients and methods}

\section{Patient Population}

The AFC (Association Française de Chirurgie) conducted a multicentric retrospective study in French ( $\mathrm{n}=20)$, Belgian $(\mathrm{n}=2)$, Canadian (Quebec, $\mathrm{n}=2$ ) and Swiss $(\mathrm{n}=1)$ centers. Patients were treated between March 1993 and December 2007. Inclusion criteria were 1) pathologic confirmation of PMP 2) patients treated with the intent of achieving an R0 resection with cytoreductive surgery combined with hyperthermic intraperitoneal chemotherapy (HIPEC) or early postoperative intraperitoneal chemotherapy (EPIC). Exclusion criteria were tumors originating from the colon, small bowel and appendiceal adenocarcinoma without a predominant mucinous component.

\section{Treatment}

Resection of PMP obeyed principles described elsewhere (17). In short, peritonectomy procedures which included a total anterior and lateral parietal peritonectomy, omentectomy and splenectomy, right and left sub-phrenic peritonectomy, pelvic peritonectomy and lesser omentectomy and cholecystectomy with stripping of the omental bursa were performed exclusively in the macroscopically pathologic areas. 
More or less extended resections of the colon, rectum, small-bowel and stomach were associated, if invaded by PMP. Intraperitoneal chemotherapy was delivered immediately after cytoreductive surgery. EPIC was performed from day 1 to day 5 after surgery, and was used during the early period of this retrospective study. HIPEC was performed with an opened abdominal cavity (Coliseum technique), or a closed one and was used during the major second period of the study.

\section{Data Forms}

A standard data form was created to retrieve information on the primary colorectal tumor, on the status of the patient prior to the combined procedure, and on previous treatment with systemic chemotherapy. The extent of PC is assessed through intraoperative exploration using the Peritoneal Cancer Index $(\mathrm{PCI})$ which scores from 0 to 3 each of the 13 defined areas of the abdominal cavity, and therefore ranges from 1 to 39 . Four $\mathrm{PCl}$ subgroups were arbitrarily defined for the analysis : 1 to 6,7 to 12,13 to 19 , and > 19. Information recorded about the combined procedure included the completeness of cytoreductive surgery, any simultaneous resection of the primary tumor and liver metastases, the presence or absence of lymph node metastases, the type of perioperative intraperitoneal chemotherapy (HIPEC or EPIC) and its modalities, and treatment with adjuvant systemic chemotherapy. Assessment of the completeness of the cancer resection (CCR) with cytoreductive surgery was done by the surgeon at the end of the procedure and classified into three categories: CCR-0 signified no macroscopic residual cancer, CCR-1, no residual nodules greater than $2.5 \mathrm{~mm}$, and CCR-2, that the diameter of the residual nodules exceeded $2.5 \mathrm{~mm}$. Information was obtained regarding the postoperative course, including postoperative deaths (within 30 postoperative days) and the cause of death. Major complications (grade 3 and 4 
complications according to the National Cancer Institute's Common Toxicity Criteria) were considered and the reasons for re-operation were detailed.

PMP was classified into 3 pathological grades according to the Ronnett classification system (4): grade 1 corresponded to disseminated peritoneal adenomucinosis (DPAM), grade 2 to peritoneal carcinomatosis with intermediate features, and grade 3 to peritoneal mucinous carcinomatosis (PMCA).

Data recorded included the most recent follow-up information, the status of the patient (alive with disease, alive without disease, died with disease, died without disease), and the site of the initial recurrence.

\section{Statistical Analysis}

The descriptive analyses of the patients included in the registry, as well as the survival analyses were performed on a per-patient basis (one record per patient). However, all procedures were considered for the analyses of postoperative morbi-mortality events (death or major complications occurring within 30 days after surgery).

Categorical variables were described in terms of frequency and percentages. The distributions of continuous variables were described with the mean, standard error, median, $1^{\text {st }}$ and $3^{\text {rd }}$ quartiles. Patient, disease and treatment characteristics were correlated with postoperative morbi-mortality events using univariate and multivariate logistic regression models, adjusted on centers, because of their strong prognostic influence.

The analysis of long-term mortality censored information after the cut-off date of December $31^{\text {st }} 2007$ since an active enquiry was performed in all centers to collect the status (dead/alive) of the patients at that date. The analysis of total mortality considered the interval from the first procedure to the date of death, the date of the 
last news, or the cut-off date, whichever came first. The analysis of recurrence or death was based on the interval from the first procedure to the date of first recurrence, the date of death, the date of the last news, or the cut-off date, whichever came first. Postoperative deaths were not excluded from the survival analysis. Patients who had CCR-2 resections with residual tumor nodules exceeding 2.5 $\mathrm{mm}$ were considered as having immediate relapses. When the date of recurrence was unknown in patients who had died, the date of death was used instead. Kaplan-Meier survival estimates were calculated, and compared between strata with the log-rank test. The influence of baseline risk factors on the hazard of death was assessed using a multiple proportional hazard regression model stratified on centers. Stratification was justified due to considerable heterogeneity in hazards between centers, and to a strong potential confounding effect on other risk factors. In all multivariate analyses, age and $\mathrm{PCl}$ were entered as continuous variables. The completeness of cytoreduction was also entered as continuous when justified by a linear trend across categories. Risk factors with a trend of significance $(p \leq 0.10)$ were retained in the final model. The SAS statistical software (Windows, V9.1) was used for all analyses.

\section{$\underline{\text { Results }}$}

\section{Patients}

From March 1993 to December 2007, 301 patients with PMP were treated in 18 Frenchspeaking centers with CRS plus PIC (5 centers did not treat PMP). The number of patients treated per center ranged from 130 to 1 . There were 190 females and 111 males and the mean age was 52 years $\left(1^{\text {st }}-3^{\text {rd }}\right.$ quartile: $44-59$; median: 52 , range: $26-$ 79). 
PMP originated from the appendix in $91 \%$ of the cases (ovary in $7 \%$, and the origin was unknown in 2\%). The circumstances leading to the discovery of PMP were : unexplained ascites leading to laparoscopy or laparotomy ( (32\%), abdominal pain $(27 \%)$, increasing abdominal girth (15\%), on imaging performed for an another reason (15\%), deterioration of general status (5\%), wound hernia (4\%), and appendicitis (2\%).

\section{Treatment Modalities}

The mean peritoneal index was $18.5\left(1^{\text {st }}-3^{\text {rd }}\right.$ quartiles: 11-26, median:18, range:9-39). Concerning the completeness of cytoreductive surgery, CCR- 0 had been achieved in $73 \%$, CCR-1 in 20\%, and CCR-2 in 7\%. Concerning intraperitoneal chemotherapy, 255 patients $(85 \%)$ had been treated with HIPEC and 46 patients $(15 \%)$ with EPIC. Hipec was done even with mitomycin $\mathrm{C}$ based-regimens during $60-120 \mathrm{~min}$. at $41-42^{\circ} \mathrm{C}$, even with oxaliplatin-based regimens during $30 \mathrm{~min}$ at $43^{\circ} \mathrm{C}$. EPIC was done with mitomycinC during day 1 and 5-fluorouracyl from day 2 to day 5. Systemic chemotherapy had been administered before or after this combined treatment in 69 patients (23\%), mainly those presenting severity of illness criteria (mean number of courses: 7.1).

\section{Mortality and Morbidity}

Thirteen patients $(4.4 \%)$ had died postoperatively. The causes of death were septic shock (9 patients) linked to abdominal infection, respiratory complications (4 patients), hematological toxicity ( 2 patients), pulmonary embolism (1 patient), and acute renal insufficiency ( 1 patient).

Grade 3-4 complications had occurred in 119 patients (40\%), and $17.5 \%(n=52)$ of all patients had been re-operated on; $8 \%(n=24)$ had a digestive fistula, 9\% (n=27) a intraperitoneal abscess, $13 \%(n=38)$ hemorrhage, 14\% $(n=42)$ a pulmonary infection, and 
$20 \%(n=58)$ grade 3-4 hematological toxicity. The median duration of hospitalization was 21 days (mean duration $26 \pm 14$ days).

The logistic regression analysis of factors which significantly increased the risk of mortality and morbidity identified two main factors, the peritoneal index $(p=0.002$, correlated with the extent and duration of surgery), and the presence of a high pathologic grade $(P M C A)(p=0.03)$.

\section{Survival}

With a mean follow-up of 88.4 months $\left(1^{\text {st }}-3^{\text {rd }}\right.$ quartile: $28-125$, median: 73$)$, the overall 1-year, 3-year, and 5-year survival rates were respectively $89.4 \%, 84.8 \%$ and $72.6 \%$ (figure 1). The 10 -year survival rate was $54.8 \%$. Median survival had not yet been reached, but it will be longer than 100 months. The disease-free survival (DFS) rate was $56 \%$ at 5 years (figure 1) and the median duration of DFS was 78 months.

There was a strong center effect $(p=0.004)$ that justified an analysis of the impact of other prognostic factors adjusted on centers (figure 2). Figure 2 shows 7 curves corresponding to the six centers which treated at least 10 patients and one curve (the lowest one) for the 11 remaining centers (which treated fewer than 10 patients per center).

In the univariate analysis (table 1), age did not exert an impact on survival unlike gender $(p=0.02$, in favor of females), the extent of peritoneal seeding $(p<0.001)$, the completeness of CRS $(p<0.001)$, the pathologic grade $(p<0.001)$ and the presence of invaded lymph nodes $(\mathrm{p}<0.001)$. Two other prognostic factors must be underlined: HIPEC seemed more efficient than EPIC $(p=0.001)$ and the results were different 
according to the centers $(p=0.0004)$. The prognosis was worse $(p=0.01)$ for patients who had received systemic chemotherapy (because it was given in advanced and high-grade cases).

The multivariate analysis identified five factors with an independent influence on survival (table 2$)$. First, the center effect $(p<0.01)$, second, the extent of peritoneal seeding $(p=0.004)$ (figure 3$)$ with a significant decline in survival when the peritoneal index was greater than 20. This index was strongly correlated with the completeness of the CRS : CCR1 and CCR-2 were only observed when the peritoneal index was high. Thirdly, the pathologic grade $(p=0.03)$ was a poor prognostic factor for PMCA. No significant difference in survival was found between DPAM and intermediate grades. The other two factors were gender $(p=0.02)$ in favor of females, and the use of HIPEC rather then EPIC $(p=0.04)$.

Multivariate analysis of disease-free survival identified two significant factors: the extent of the peritoneal seeding $(p<0.001)$ (strongly correlated with the CCR-status), and the center's experience $(p=0.006)$.

In the group of 206 patients with a CCR-0 resection, the 5-year and 10-year survival rates were $84 \%$ was $61 \%$ respectively. It is noteworthy that two factors became nonsignificant in the univariate analysis : gender and the pathologic grade. Only one factor continued to exert a prognostic impact : the extent of peritoneal seeding $(p=0.004)$, while HIPEC was marginally better $(p=0.07)$ than EPIC.

\section{Discussion}

This study reports the results of the first multicentric retrospective analysis of 301 patients with diffuse PMP treated by cytoreductive surgery combined with 
perioperative intraperitoneal chemotherapy. Postoperative mortality was $4 \%$, and grade 3-4 morbidity was $40 \%$. The 5 -year survival rate was $72.6 \%$ and median diseasefree survival was 78 months. Median survival has not yet been attained but was longer than 100 months.

Survival. This study reports on the largest series of patients with PMP ever published after the monocentric series of 501 cases reported by Sugarbaker (11). Compared to the exceptional expertise of Sugarbaker, it presents results from 18 French-speaking centers, and adequately reflects the management of PMP in real-life settings where the experience of such treatment is very unequal from one center to another. It is always difficult to extrapolate results from a monocentric experience to other centers, due to considerable heterogeneity in selection criteria, in CRS and intraperitoneal chemotherapy techniques. Our study effectively underlines the importance of the experience of the center in the survival results. Due to a healthy degree of scepticism among some oncologists, any multicentric study collecting data from a large number of centers is particularly useful, even if the experience and the techniques differ considerably from one center to another. This trial concerns a collaborative effort of 25 French-speaking centers, which included 1290 patients with primary or digestive peritoneal carcinomatosis treated by CRS combined with PIC to evaluate the efficiency of this combined approach (18 of them have treated PMP). Due to its retrospective nature, this study suffers from many potential biases in the selection of patients and in treatments. Nonetheless, it has allowed us to present a large number of patients treated in many centers and to draw conclusions.

Also, the 5-year overall survival rate of $72.6 \%$ for PMP represents the worst results that can be obtained with CRS combined with PIC because it takes into account the learning curves of 18 centers, and because progress in patient selection and in the quality of 
surgery increases with experience. This overall survival rate is identical to the $72 \%$ reported by Sugarbaker in his cohort of 501 patients (11). Thus, our multicentric study corroborates the results of the largest monocentric study. If we analyze the other four trials which included more than 100 patients treated with this combined approach, our survival results are better than those reported by Zoetmulder (13) and Loggie (14), close to those of Chua et al. (16) but worse than those reported by Elias (15) who included only patients whose resection was complete or sub-complete (CCR-0 or CCR1).

Moreover, a mortality rate of $4 \%$ and a morbidity rate of $40 \%$ for this combined approach are the sort of rates that would be obtained with any kind of complex oncologic surgery such as oesophagectomy or duodeno-pancreatectomy. These rates are therefore acceptable face to benefits for overall and disease-free survival.

The results of the conventional treatment of PMP mainly based on repeated surgical debulking have been reported in two series $(5,6)$. Gough et al. (5) reported a 5-year survival rate of $53 \%$, with a $97 \%$ recurrence rate at 10 years in 56 PMP patients who underwent serial debulking and were selectively treated with intraperitoneal radiotherapy or chemotherapy between 1957 and 1983. Minner et al. (6) reported an $88 \%$ recurrence rate at 5 years in 97 PMP patients treated with serial debulking, systemic chemotherapy and/or delayed intraperitoneal 5-fluorouracil over a 22-year period. The $3 \%$ and $12 \%$ disease-free survival rates are well below the $56 \%$ rate we observed in our series. Sugarbaker and Zoetmulder also reported higher rates, $47 \%$ and $61 \%$, respectively. All these results are probably due to the superiority of the combined over the conventional approach. In France, this combined approach has become the gold standard treatment when feasible (18). 
Prognostic factors. The multivariate analysis of our series identified four significant and independent prognostic factors, adjusted on centers: the extent of the disease, the pathologic grade, gender, and the use of hyperthermia. One of these factors, namely the extent of the disease, was not identified in the five earlier series of more than 100 patients treated with the combined approach. In contrast, the completeness of cytoreduction was statistically significant in three $(12,14,16)$. The pathologic grade was not retained in three series $(12-15)$, but selected in two $(13,16)$ which reported only 31 CCR-0 resections in 103 treated patients and 73 CCR-O resections in 106 treated patients for the first and the second study respectively.

Thus, new information is emerging from our multicentric study.

First, this multicentric study underlines the influence of the center in which the procedure was performed and this led us to perform a multivariate analysis adjusted on centers. Centers with less experience had a lower rate of complete cytoreduction and poorer survival results. The fact that incomplete cytoreduction in the 174 patients reported by Glehen et al (23), resulted in only 15\% of patients alive at 5 years argues in favor of exclusively entrusting this approach to experienced, good quality centers in the future.

Second, the extent of peritoneal seeding has a potent prognostic impact, even if this impact is probably lower than for patients with colorectal peritoneal carcinomatosis (18-21). In our series, the 5-year survival rate was only $57 \%$ for patients with a peritoneal index exceeding 19 , whereas it was $83 \%$ for the other patients. We also established that the completeness of cytoreduction was strongly correlated with the disease extent (peritoneal cancer index), and also with the pathologic grades (data not shown). Finally, extensive PMP with high pathologic grades are the most frequently incompletely resected lesions and mainly in inexperienced centers. 
Third, the pathologic grade had a significant prognostic impact on the whole series, but it disappeared when only the 206 patients with a complete CCR-0 resection were considered. Thus complete cytoreductive surgery is able to reduce the negative prognostic impact of the pathologic grade as previously pointed out by Elias et al. (15). Fourth, survival was better among female patients in the whole series, but gender was not statistically significant when only CCR-0 patients were taken into account. Thus, male patients more frequently presented with extended and incompletely resectable PMP than female patients.

Fifth, survival results were better with HIPEC than with EPIC. Glehen et al. (23) already reported the superiority of HIPEC over EPIC in a retrospective study evaluating patients treated with incomplete CRS. Our results could stem from a bias because EPIC was mainly used during the earlier period of the study. Although experimental studies are also in favor of the use of hyperthermia (24), its benefit should be confirmed in a prospective study.

Finally, it is noteworthy that the extent of peritoneal seeding was the only prognostic factor identified in the multivariate analysis in the group of patients with a CCR-0 resection.

In conclusion, this multicentric study of 301 patients with PMP confirms the promising results reported earlier by Sugarbaker and a few other experienced teams using the combination of cytoreductive surgery with perioperative intraperitoneal chemotherapy to treat PMP. It also establishes that the extent of peritoneal seeding and the completeness of cytoreduction exert a greater impact on survival than the pathologic grade. 
Acknowledgements: The authors thank Lorna Saint Ange for editing and Nadine Bossard and Florent Boutitié for statistical analysis.

\section{References:}

1. Sugarbaker PH. New standard of care for appendiceal neoplasms and pseudomyxoma peritonei syndrome. Lancet Oncol 2006; 7: 69-76

2. Brendan MJ, Cecil TD. The etiology, clinical presentation and management of pseudomyxoma peritonei. Surg Oncol Clin N Am 2003; 12: 585-603

3. Semino-Mora C, Liu H, McAvoy T, Nieroda C, Studeman K, Sardi A, et al. Pseudomyxoma peritonei : is disease progression related to microbial agents? A study of bacteria, MUC2 and MUC5AC expression in disseminated peritoneal adenomucinosis and peritoneal mucinous carcinomatosis. Ann Surg Oncol 2008; 15: 1414-1423

4. Ronnett BM, Zahn CM, Burman RJ,Kass ME, Sugarbaker PH, Shmookler BM. Disseminated peritoneal adenomucinosis and peritoneal carcinomatosis. A clinicopathologic analysis of 109 cases with emphasis on distinguishing pathologic features, site of origin, prognosis and relationship to"pseudomyxoma peritonei”. Am J Surg Pathol 1995; 19: 1390-1409

5. Gough DB, Donohue JH, Schutt AJ, Gonchoroff N, Goellner JR, Wilson TO, et al. Pseudomyxoma peritonei. Long tern patient survival with an aggressive regional approach. Ann Surg 1994; 219: 112-119

6. Miner TJ, Shia J, Jacques DP, Klimstra DS, Brennan MF, Coit DG. Long-term survival following treatment of pseudomyxoma peritonei: an analysis of surgical therapy. Ann Surg 2005; 241: 300-308

7. Yan TD, Black D, Savady R, Sugarbaker PH. A systematic review of the efficacy of cytoreductive surgery and perioperative intraperitoneal chemotherapy for pseudomyxoma peritonei. Ann Surg Oncol 2007; 14: 484-492

8. Sugarbaker PH, Cuniffe W, Belliveau JF, de Bruin E, Graves T. Rationale for perioperative intraperitoneal chemotherapy as a surgical adjuvant for gastrointestinal malignancy. Reg Cancer Treat 1988; 1: 66-79.

9. Hettinga JV, Konings AW, Kapringa HH. Reduction of cellular cisplatin resistance by hyperthermia. A review. Int J Hyperthermia $1997 ; 13: 439-57$ 
10. Murakami A, Koga S, Maeta M. Thermochemosensitivity: augmentation by hyperthermia of cytotoxicity of anticancer drugs against human colorectal cancer, measured by the human tumor clonogenic assay. Oncology 1988; 45: 236-41.

11. Gonzalez-Moreno S, Sugarbaker P. Right hemicolectomy does not confer a survival advantage in patients with mucinous carcinoma of the appendix and peritoneal seeding. $\mathrm{Br}$ J Surg 2004; 91: 304-311

12. Sugarbaker $P$, Chang D. Results of treatment of 385 patients with peritoneal surface spread of appendiceal malignancy. Ann Surg Oncol 1999; 6: 727-731

13. Smeenk RM, Verwaal V, Antonini N, Zoetmulder F. Survival analysis of pseudomyxoma peritonei patients treated by cytoreductive surgery and hyperthermic intraperitoneal chemotherapy. Ann Surg 2007; 245: 104-109

14. Stewart JH, Shen P, RussellGB, Bradley RF, Hundley JC, Loggie BL, et al. Appendiceal neoplasms with peritoneal dissemination: outcomes after cytoreductive surgery and intraperitoneal hyperthermic chemotherapy. Ann Surg Oncol 2006; 13: 624-634

15. Elias D, Honoré C, Ciuchundea R, Billard V, Raynard B, Lo Dico R, et al. Peritoneal pseudomyxoma: results of a systematic policy of complete cytoreductive surgery and hyperthermic intraperitoneal chemotherapy. Br J Surg 2008; 95: 1164-1171

16. Chua TC, Yan TD, Smigielski ME, Zhu KJ, Ng KM, Zhao J, et al. Long-term survival in patients with pseudomyxoma peritonei treated with cytoreductive surgery and perioperative intraperitoneal chemotherapy: 10 years of experience from a single institution; Ann Surg Oncol 2009; 16: 1903-1911

17. Sugarbaker PH. Peritonectomy procedures. Ann Surg 1995; 221: 29-42

18. Recommandations de la Société Française de Chirurgie Digestive (SFCD) et de l'Association de Chirurgie Hépato-biliaire (ACHBT). Cancérologie digestive : pratiques chirurgicales. J Chir (Paris) 2009 ; 146, supplément 2 : 560-562 
19. Elias D, Gilly F, Boutitie F, Quenet F, Bereder JM, Mansvelt B et al. Peritoneal colorectal carcinomatosis treated with surgery and perioperative intraperitoneal chemotherapy. Analysis of 523 patients from a multicentric French Study. J Clin Oncol 2009 (in press)

20. Gomez da Silva R, Sugarbaker PH. Analysis of prognostic factors in seventy patients having a complete cytoreduction pus perioperative intraperitoneal chemotherapy for carcinomatosis from colorectal cancer; J Am Coll Surg 2006; 203: 878-886

21. Verwaal VJ, van Ruth S, Witkamp A, et al. Long-term survival of peritoneal carcinomatosis of colorectal origin. Ann Surg Oncol 2005; 12:65-71.

22. Elias D, Blot F, El Otmany A, et al. Curative treatment of peritoneal carcinomatosis arising from colorectal cancer by complete resection and intraperitoneal chemotherapy. Cancer $2001 ; 92: 71-6$.

23. Glehen O, Mohamed F, Sugarbaker PH. Incomplete cytoreduction in 174 patients with peritoneal carcinomatosis from appendiceal malignancy. Ann Surg 2004; 240: 278-285

24. Koga S, Hamazoe R, Maeta M, et al. Treatment of implanted peritoneal cancer in rats by continuous hyperthermic peritoneal perfusion in combination with an anticancer drug. Cancer Research 1984 ; 44 : 1840-42 
Table 1 : Univariate analysis of prognostic factors.

\begin{tabular}{|c|c|c|c|c|}
\hline Variable & Number & 3-y survival (\%) & 5-y survival (\%) & $\mathrm{p}$ \\
\hline $\begin{array}{c}\text { Gender Female } \\
\text { Male }\end{array}$ & 190 & 88 & $\begin{array}{l}77 \\
66\end{array}$ & 0.02 \\
\hline Male & 111 & 84 & 66 & \\
\hline $\begin{aligned} \text { Age }< & 53 y \\
& \geq 53 y\end{aligned}$ & $\begin{array}{l}162 \\
139\end{array}$ & $\begin{array}{l}87 \\
82\end{array}$ & $\begin{array}{l}71 \\
73\end{array}$ & 0.09 \\
\hline \multicolumn{5}{|l|}{ IV chemotherapy } \\
\hline No & 229 & 88 & 78 & 0.01 \\
\hline Yes & 72 & 72 & 68 & \\
\hline \multicolumn{5}{|c|}{ Extent of Peritoneal Disease ${ }^{1}$} \\
\hline $1-6$ & 34 & 92 & 79 & $<0.001$ \\
\hline $7-12$ & 47 & 92 & 83 & \\
\hline $13-19$ & 59 & 92 & 84 & \\
\hline$>19$ & 117 & 74 & 57 & \\
\hline \multicolumn{5}{|c|}{ Size of remaining tumor ${ }^{2}$} \\
\hline $0 \mathrm{~mm}$ & 201 & 90 & 84 & $<0.001$ \\
\hline$<2.5 \mathrm{~mm}$ & 55 & 71 & 58 & \\
\hline$>2.5 \mathrm{~mm}$ & 19 & 67 & 25 & \\
\hline \multicolumn{5}{|c|}{ Lymph node involvement ${ }^{3}$} \\
\hline No & 243 & 88 & 78 & $<0.001$ \\
\hline Yes & 7 & 0 & 0 & \\
\hline \multicolumn{5}{|l|}{ Pathologic grade ${ }^{4}$} \\
\hline DPA & 136 & 93 & 85 & $<0.001$ \\
\hline Intermediate & 71 & 90 & 84 & \\
\hline PMC & 59 & 69 & 47 & \\
\hline \multicolumn{5}{|c|}{ Type of intraperitoneal chemo } \\
\hline HIPEC & 255 & 90 & 79 & 0.001 \\
\hline EPIC & 46 & 63 & 54 & \\
\hline \multicolumn{5}{|l|}{ Center } \\
\hline Best results & 36 & 87 & 77 & 0.02 \\
\hline Worst results & 9 & 47 & 45 & \\
\hline
\end{tabular}

\footnotetext{
According to the peritoneal index, 44 were not reported

${ }^{2}$ After cytoreductive surgery ( = completeness of the resection), 26 were not reported

${ }^{3} 51$ were not reported, ${ }^{4} 35$ were not reported

DPA = diffuse peritoneal adenomucinosis

$P M C=$ Peritoneal mucinous carcinomatosis

HIPEC = hyperthermic intraperitoneal chemotherapy

EPIC = Early postoperative intraperitoneal chemotherapy
} 
Table 2: Multivariate analysis of prognostic factors for overall survival of 301 , patients treated by cytoreductive surgery combined with perioperative intraperitoneal chemotherapy

\begin{tabular}{lcll} 
Variable & $p$ & Hazard ratio & $95 \% \mathrm{Cl}$ \\
\hline Peritoneal index (1) & 0.004 & 1.042 & $1.013-1.072$ \\
Center & 0.001 & 0.469 & $0.286-0.797$ \\
Histologic grade (2) & 0.02 & 0.338 & $0.133-0.859$ \\
Sex & 0.02 & 0.554 & $0.330-0.931$ \\
HIPEC vs EPIC & 0.04 & 4.476 & $1.051-19.053$
\end{tabular}

(1) For each point in the peritoneal index. Each additional point increases the relative risk of death, i.e. by $4.2 \%$.

(2) In three categories: . Passing from DPA or intermediate category to PMC increases the risk of death by $33.8 . \%$. 
Figure Legends:

Figure 1: Overall and disease-free survival of the 301 patients with PMP treated with CRS + HIPEC

Figure 2: Overall survival according to the centers $(p<0.001)$ (the names of centers are censured).

Figure 3: Overall survival according to the peritoneal index $(p=0.004)$ 
Figure 1:

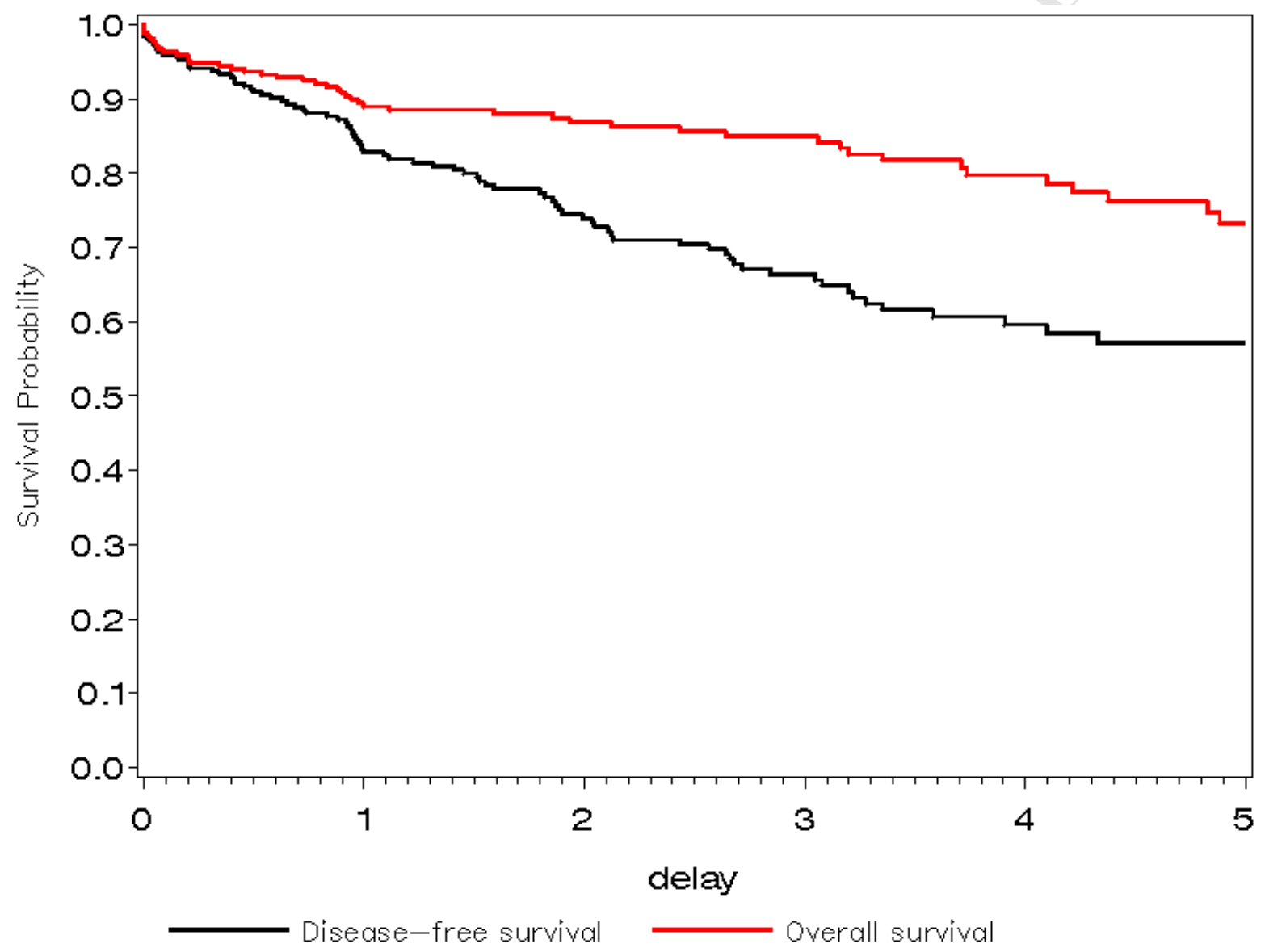


Figure 2 :

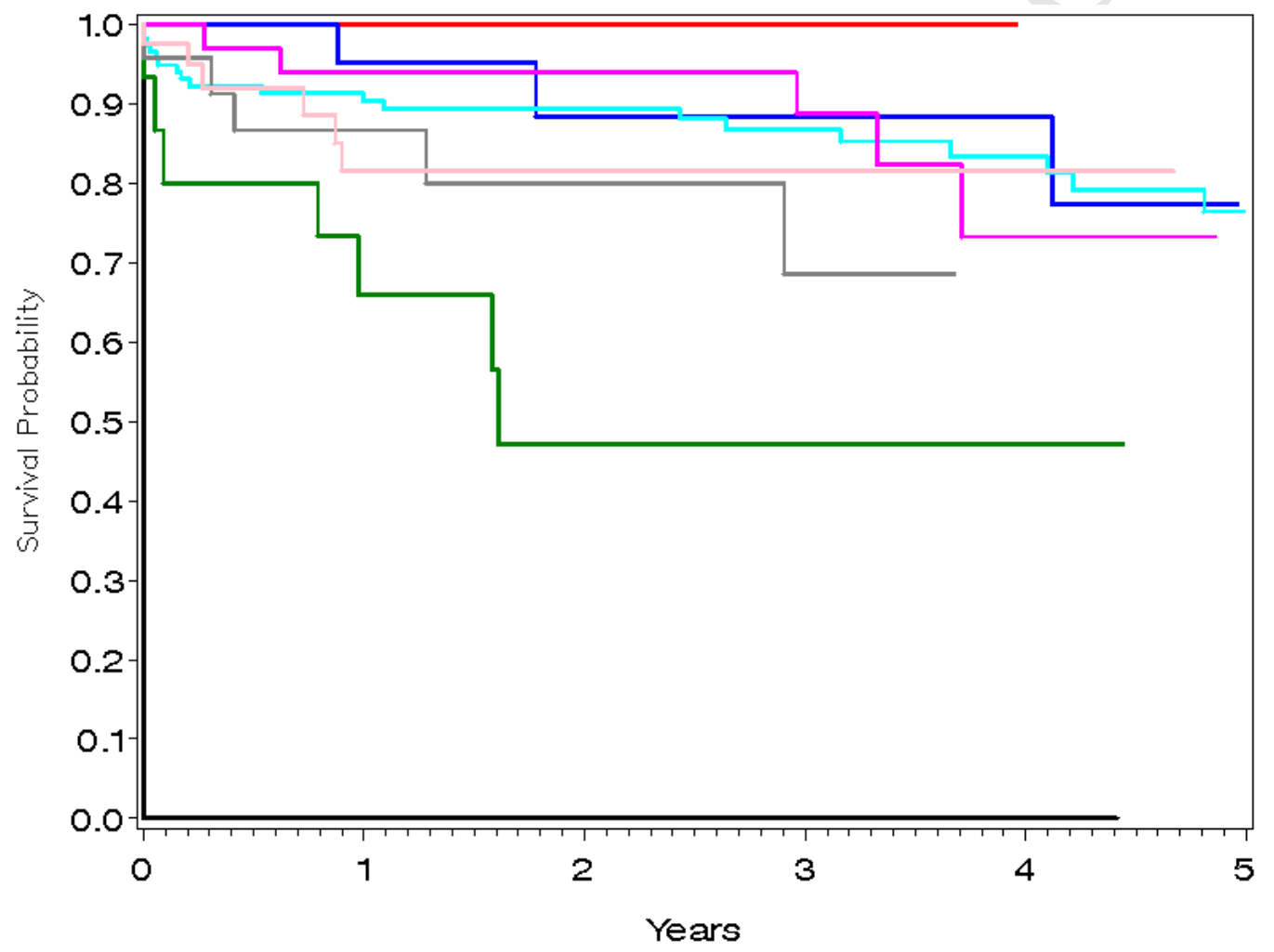


Figure 3 :

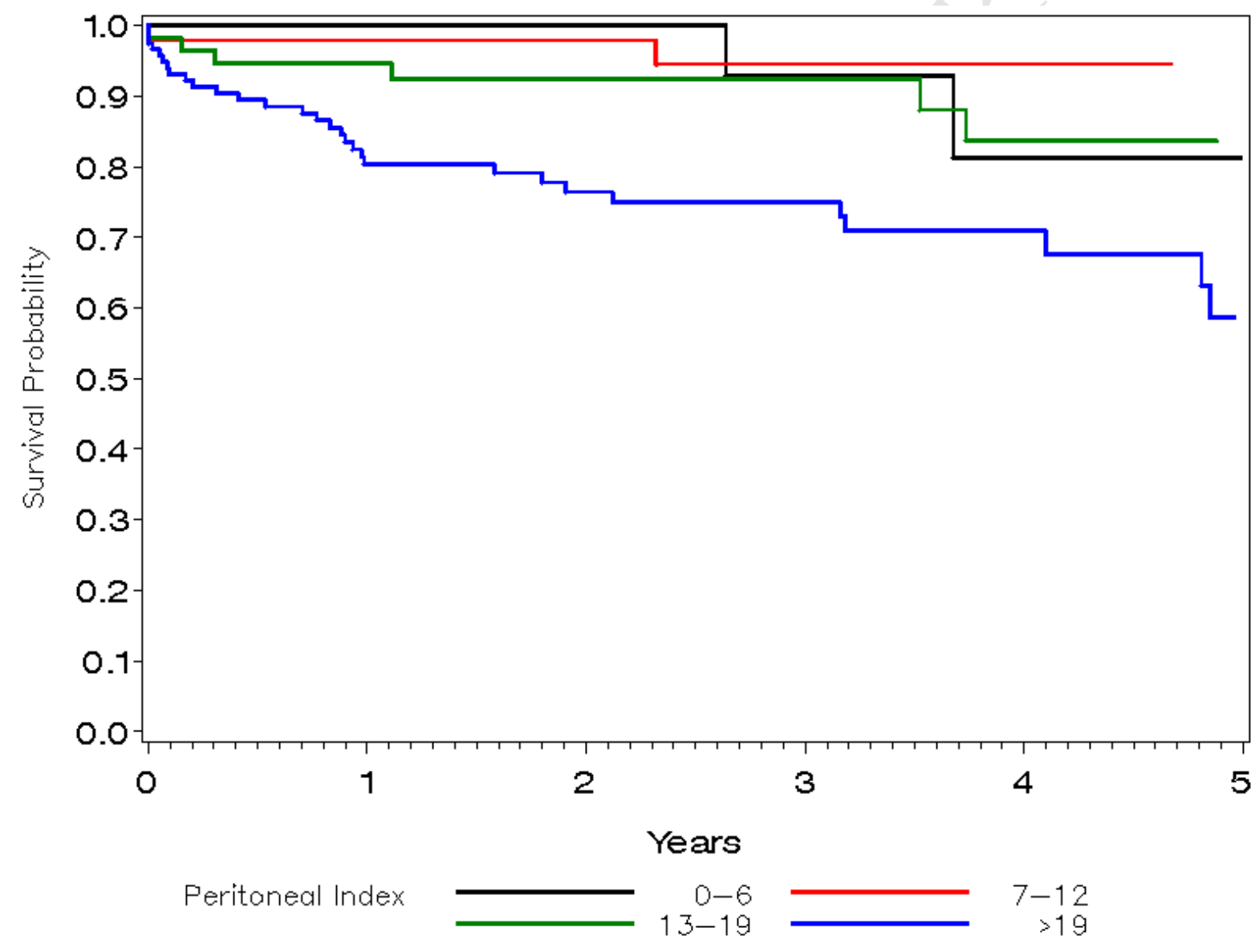

